\title{
The effect of music on eating behavior
}

\author{
THOMAS C. ROBALLEY, COLLEEN McGREEVY, RICHARD R. RONGO, \\ MICHELLE L. SCHWANTES, PETER J. STEGER, \\ MARIE A. WININGER, and ELIZABETH B. GARDNER \\ Fairfield University, Fairfield, Connecticut
}

\begin{abstract}
The effects of music tempo on number of bites per minute and total time of meal were studied. Eleven subjects unknowingly participated in the study. Three music conditions were used: fast tempo, slow tempo, and no music. A significant increase in the number of bites per minute was found; the effect was largest for fast-tempo music, which suggests arousal as a possible mediator. No difference was found in total time of meal. A questionnaire revealed no evidence that subjects were aware of the music.
\end{abstract}

In the past, different types of music have been found to have different effects upon emotions, physiological reactions, and behavior. Smith and Morris (1976) reported that during a cognitive task, "stimulative" music maintained an elevated emotionality level, whereas "sedative" and control group means decreased. Stimulative music has been reported to increase pupil dilation, whereas sedative music has caused pupil constriction (Slaughter, 1957). Even purchasing behavior is affected by different types of music. Milliman (1982), studying purchasing behavior and speed of movement through a grocery store, found that the tempo of background music significantly affected both the pace of in-store traffic flow and sales volume. Traffic flow was found to be significantly slower with slow-tempo music than with fast-tempo music. The nomusic condition did not differ significantly from either. However, higher sales volumes were found with slowtempo music than with fast-tempo music. Randomly selected customers were asked outside the supermarket whether they recalled music playing while they were shopping. Interestingly, Milliman's subjects failed to reveal any significant variations in music awareness; that is, subjects were no more and no less likely to recall the music, regardless of the music condition.

Milliman's (1982) research suggests the possibility that music tempo influences the speed of other behaviors, with fast-tempo music having an increasing effect and slowtempo having a decreasing effect relative to a no-music treatment as a baseline of behavior. A setting in which music is encountered but frequently is not attended to is that of a restaurant or cafeteria. The purpose of the present study was to examine the effects of music tempo on eating behavior in such a setting. The following hypotheses were tested:

(1) Fast-tempo music would result in an increase in eating speed, whereas slow-tempo music would result in a

The authors are grateful to James D. Fitzpatrick for his cooperation during the course of the study. Requests for reprints should be addressed to Elizabeth B. Gardner, Department of Psychology, Fairfield University, Fairfield, CT 06430-7524. decrease in eating speed, both relative to the no-music condition.

(2) Subjects in either music condition would be no more likely to express an awareness of the music being played than would subjects in the no-music condition. In other words, the music would affect behavior without the subjects' being aware.

\section{METHOD}

Subjects

There were 11 subjects ( 10 men, 1 woman), ranging in age from 25 to 60 years, who were patrons of the Fairfield University faculty and staff cafeteria and were unaware of their involvement in the study.

\section{Materials and Procedure}

Two tapes, 60 min long and composed of only instrumental, nonclassical selections, were used. A sound-level meter was used during the recording to keep the volume at a constant level. The tapes were played at the same loudness setting on the central public address system of the building housing the cafeteria.

There were three music conditions: (1) slow-tempo music (mean beats per minute $=56, \mathrm{SD}=7.8$ ); (2) fast-tempo music (mean beats per minute $=122, \mathrm{SD}=19.6$ ); and (3) no music. [Milliman, 1982, used music with an average of 60 beats per minute for slow music and 108 beats per minute for fast music.] Music was played between noon and 1:30 p.m. on the working days of the week in the sequence fast music, slow music, and no music. This pattern was repeated throughout the course of study, which lasted 16 days. Each subject was observed under each of the three music conditions by teams of two experimenters posing as patrons of the cafeteria. The order of conditions under which each subject was observed varied.

The two eating-speed measures used were average bites per minute and total time of the meal. Once the subjects had taken the first bite (bites were restricted to mouthfuls not consisting of a beverage), timers were started. After a 2-min interval, the number of bites were counted for $5 \mathrm{~min}$. Another 2-min interval and a second 5-min period of observation followed. Timing was stopped after the last bite of the meal. Data for the two 5-min periods were combined in the computation of mean bites per minute for each subject in each condition.

A slow-music day and a no-music day were chosen for evaluating music awareness by means of a questionnaire. After they had left the cafeteria, 22 patrons were asked to take a moment to complete the questionnaire, which was composed of two questions: "Do you recall music being played in the Faculty Dining Room while you were eating?"; "Would you like music to be played in the Faculty Dining Room?" Boxes were provided for them to check yes, not sure, or no. 


\section{RESULTS}

The mean numbers of bites per minute, were, for fasttempo music $4.40(\mathrm{SD}=1.57)$, for slow-tempo music, $3.83(\mathrm{SD}=1.18)$, and for no music, $3.23(\mathrm{SD}=1.06)$. A treatments $\times$ subjects analysis of variance confirmed that music significantly affected eating speed $[F(2,20)=$ $5.19, \mathrm{p}<.025]$.

No significant differences were found for the total time of meal.

To measure the subjects' awareness of the background music, a chi-square was used. The results were not significant $\left(\chi^{2}(2)=4.73, \mathrm{p}<.10\right)$; therefore, it may be that the subjects did not consciously perceive the music.

\section{DISCUSSION}

Background music significantly increased the average number of bites per minute. This finding supports the hypothesis that eating speed would increase with fast-tempo background music. The hypothesis that eating speed would decrease with slow-tempo music was not supported. There was, however, a clear tendency for an increasing number of bites per minute from no music through slow-tempo music to fast-tempo music. This would appear to have been due to an arousal effect, and is in agreement with Mrudula's (1974) finding that an increased rhythm/tempo results in an increase in productivity for noncomplex tasks. Mussulman (1974, p. 96) stated that background music has the "practical, economic effect of improving efficiency, morale, safety, and increasing productivity among employees or satisfaction among customers."

In a behavioral study by Konz and McDougal (1968), in which the effect of music tempo on driving control was tested, both Tijuana Brass (fast-tempo) music and slow-tempo music resulted in faster driving speeds than no music. Similarly, Diserens and Fine (1939) found that music of any kind increased endurance and reduced or delayed the course of fatigue. Stirring/fast-tempo music was associated with a $70 \%$ increase in efficiency and a $50 \%$ decrease in fatigue, and soothing/slow-tempo music produced a $60 \%$ increase in efficiency and a $40 \%$ decrease in fatigue. They also stated that music in general tends to increase the extent and rapidity of voluntary movements. This suggests that music serves an "arousal" function (Radocy \& Boyle, 1979). Simpson (1976) found, with brain-injured children, that background music contributes to hyperactivity; task success, however, improved. Simpson suggested that background music creates a state of arousal that blocks out other distractors. Such an "arousal" state could cause an increase in eating speed.

This "arousal" state was recorded by Myasishchev and Gotsdiner (1975). EEG and polygraphic data were collected as subjects listened to music. These recordings were then analyzed in relation to each sub- ject's reaction to the music. Myasishchev and Gotsdiner found that the EEG and polygraphic changes were not always consistent with the subject's reaction to the music, suggesting that the subject was unaware of the physiologic changes: The subject was unaware of the "arousal" state. This may explain why the subjects of Milliman's (1982) study and those in the present study were no more and no less likely to recall the music regardless of the music condition. If a subject is unaware of a physiologic state caused by a stimulus, the subject may also be unaware of the stimulus. Indeed, Nisbett and Wilson (1977) described numerous instances in which behavior is demonstrably influenced by stimuli that are not consciously available to the subject.

The results of the present experiment indicate that music can even affect the speed at which we eat.

\section{REFERENCES}

Diserens, C., \& Fine, H. (1939). A psychology of music: The influence of music on behavior. Cincinnati, $\mathrm{OH}$ : University of Cincinnati Press.

Konz, S., \& McDougaL, D. (1968). The effect of background music on the controlled activity of an automobile driver. Human Factors, 10, 233-244.

Milliman, R. (1982). Using background music to affect the behavior of supermarket shoppers. Journal of Marketing, 46, 86-91.

Mrudula, N. (1974). Rhythm and work. Scientia Paedogogica Experimentalis, 11, 95-102.

Mussulman, J. A. (1974). The uses of music: An introduction to music in contemporary American life. Englewood Cliffs, NJ: Prentice-Hall.

Myasishchev, V., \& Gotsdiner, A. (1975). The effects of music on man: Electroencephalographic and psychological indicators. Voprosy Psikhologii, 1, 54-67.

NisbetT, R., \& WiLSON, T. (1977). Telling more than we can know: Verbal reports on mental processes. Psychological Review, 84, 231-249.

RADOCY, R., \& Boyle, J. (1979). Psychological foundations of musical behavior. Springfield, IL: Charles C Thomas.

Simpson, S. (1976). The influence of background music on the behavior of brain-injured children. Israel Annals of Psychiatry and Related Disciplines, 14, 275-279.

Slaughter, F. (1957). The effects of stimulative and sedative types of music on normal and abnormal subjects as indicated by pupillary reflexes. Psychological Reports, 3, 183-187.

SMITH, C., \& MoRRIS, L. (1976). Effects of stimulative and sedative music on cognitive and emotional components of anxiety. Psychological Reports, 38, 1187-1193.

(Manuscript received for publication January 21, 1985.) 